\title{
Effect of drug content and agglomerate size on tabletability and drug release characteristics of bromhexine hydrochloride- -talc agglomerates prepared by crystallo-co-agglomeration
}

\author{
NAMDEO JADHAV ${ }^{1}$ \\ ATMARAM PAWAR ${ }^{2}$ \\ ANANT PARADKAR $2,3, *$ \\ ${ }^{1}$ Department of Pharmaceutics \\ Bharati Vidyapeeth College of \\ Pharmacy, Kolhapur-416013 \\ Maharashtra State, India \\ 2 Department of Pharmaceutics \\ Poona College of Pharmacy \\ Bharati Vidyapeeth University \\ Erandwane, Pune-411038 \\ Maharashtra State, India \\ ${ }^{3}$ Institute of Pharmaceutical Innovation \\ University of Bradford, Bradford \\ West Yorkshire, United Kingdom \\ BD7 1DP
}

Aceppted December 31, 2009
The objective of the investigation was to study the effect of bromhexine hydrochloride (BXH) content and agglomerate size on mechanical, compressional and drug release properties of agglomerates prepared by crystallo-co-agglomeration (CCA). Studies on optimized batches of agglomerates (BXT1 and BXT2) prepared by CCA have showed adequate sphericity and strength required for efficient tabletting. Trend of strength reduction with a decrease in the size of agglomerates was noted for both batches, irrespective of drug loading. However, an increase in mean yield pressure (14.189 to 19.481) with an increase in size was observed for BXT2 having BXH-talc (1:15.7). Surprisingly, improvement in tensile strength was demonstrated by compacts prepared from BXT2, due to high BXH load, whereas BXT1, having a low amount of BXH (BXH-talc, 1:24), showed low tensile strength. Consequently, increased tensile strength was reflected in extended drug release from BXT2 compacts (Higuchi model, $R^{2}=0.9506$ to 0.9981$)$. Thus, it can be concluded that interparticulate bridges formed by $\mathrm{BXH}$ and agglomerate size affect their mechanical, compressional and drug release properties.

Keywords: crystallo-co-agglomeration, agglomerate size, drug content, compression, extended release

Crystallo-co-agglomeration (CCA) is a novel particle size enlargement technique devised by Kadam et al. $(1,2)$ to overcome the limitations of spherical crystallization. Using CCA, spherical agglomerates of low dose and high dose drugs, and two or more drugs in combination with or without diluent, can be obtained, whereas the spherical crystallization technique can be used for size enlargement of high dose drugs only (3). To date, CCA has been used for size enlargement of low dose bromhexine hydrochloride (BXH) and talc (4), ibuprofen-talc (5), ibuprofen-paracetamol $(6,7)$ and naproxen-starch

\footnotetext{
* Correspondence; e-mail: arparadkar@rediffmail.com
} 
N. Jadhav et al:: Effect of drug content and agglomerate size on tabletability and drug release characteristics of bromhexine hydrochloride-talc agglomerates prepared by crystallo-co-agglomeration, Acta Pharm. 60 (2010) 25-38.

(8). Studies have demonstrated that CCA generates spherical agglomerates having excellent micromeritic properties, satisfactory mechanical strength and direct compressibility.

However, an interesting observation noted for crystallo-co-agglomerates of ibuprofen-talc was its deformation during compression, rather than fracture (5). Hence, an attempt was made to prepare a heterogeneous matrix system of deformable talc agglomerates containing the low dose drug BXH (4). Simultaneously, rapidly disintegrating compacts obtained from directly compressible spherical agglomerates of naproxen and disintegrant (starch and sodium starch glycolate) have also been reported (8). Work on CCA contributed from our laboratory has concluded that hydroxypropyl methyl cellulose (HPMC $50 \mathrm{cps}$ ) and poly ethylene glycol (PEG 6000) were found to impart sphericity, strength and compressibility to the agglomerates. Tween 80 was found to aid the emulsification of internal phase during agglomeration (3-5). But, studies elucidating the effect of drug content and agglomerate size on tabletability and drug release characters of spherical agglomerates have not been carried out to date.

Garekani et al. (9) have studied the effect of the particle size of paracetamol on compactibility and compressibility and have observed that larger size particles undergo fragmentation during compression resulting in better binding in compacts. Inverse relationship between the square root of particle size and tensile strength of the tablet has been established by Shotton and Ganderton (10). Direct proportionality between a specific surface area of particles and tablet strength has been observed by Vormans et al. (11), who attributed increased tablet strength to the increase in the bonding surface area due to decreased particle size.

The present work reports preparation of spherical agglomerates of low dose BXH using inert, inexpensive, water insoluble diluent talc $(12,13)$ by the CCA technique, and evaluation of spherical agglomerates containing BXH-talc (1:24) and 1:15.7 for micromeritic, mechanical, compressional and drug release properties.

\section{EXPERIMENTAL}

\section{Materials}

Bromhexine hydrochloride was a gift of IPCA Laboratories Ltd. (India) and hydroxypropyl methyl cellulose 50 cps of Colorcon Asia Pvt. Ltd. (India). Talc (Indian Pharmacopoeia grade) was supplied by Get-Rid Pharma (India). Polyethylene glycol 6000 (BDH Chemicals, India), dichloromethane (Merck Ltd, Maharashtra, India), Tween 80 and all other chemicals were of analytical grade.

\section{Process development}

The CCA process was carried out in a Morishima vessel (1000 mL capacity) using a propeller type stirrer and walled baffle designed by Morishima et al. (14) (Remi Udyog Ltd., India) for agitation.

Homogeneous powder mixture of talc, BXH, HPMC $50 \mathrm{cps}$ and Tween 80 (polysorbate 80 ) was wetted by dichloromethane (DCM, $30 \mathrm{~mL}$ ) in the Morishima vessel and sti- 
N. Jadhav et al:: Effect of drug content and agglomerate size on tabletability and drug release characteristics of bromhexine hydrochloride-talc agglomerates prepared by crystallo-co-agglomeration, Acta Pharm. 60 (2010) 25-38.

Table I. Composition and conditions of the agglomeration process

\begin{tabular}{|c|c|c|c|c|c|c|c|c|c|c|}
\hline \multirow[b]{2}{*}{ Batch } & \multicolumn{7}{|c|}{ Ingredient } & \multirow{2}{*}{$\begin{array}{c}\text { Total } \\
(\%)\end{array}$} & \multirow{2}{*}{$\begin{array}{l}\text { Stirrer } \\
\text { speed } \\
(\mathrm{rpm})\end{array}$} & \multirow{2}{*}{$\begin{array}{l}\text { Agglome- } \\
\text { ration } \\
\text { time } \\
\text { (min) }\end{array}$} \\
\hline & $\begin{array}{c}\text { BXH } \\
(\%, m / m)\end{array}$ & $\begin{array}{c}\text { Talc } \\
(\%, m / m)\end{array}$ & $\begin{array}{c}\text { HPMC } 50 \\
\text { cps }(\%, \\
m / m)\end{array}$ & $\begin{array}{c}\text { PEG } 6000 \\
(\%, m / m)\end{array}$ & $\begin{array}{l}\text { Tween } 80 \\
(\%, m / m)\end{array}$ & $\begin{array}{l}\text { PVP K-30 } \\
(\%, m / m)\end{array}$ & $\begin{array}{c}\text { PVA }(\% \\
m / m)^{\mathrm{a}}\end{array}$ & & & \\
\hline BXT1 & 3.6 & 86.9 & 3.6 & 4.5 & 1.4 & NA & NA & 100 & $800 \pm 50$ & $90 \pm 10$ \\
\hline BXT2 & 5.4 & 85.1 & 3.6 & 4.5 & 1.4 & NA & NA & 100 & $950 \pm 50$ & $150 \pm 10$ \\
\hline ВXT3 & 3.7 & 89.0 & 3.0 & 2.8 & 1.4 & 0.1 & NA & 100 & $800 \pm 50$ & $90 \pm 10$ \\
\hline BXT4 & 3.7 & 89.0 & 3.1 & 2.8 & 1.4 & 0.1 & NA & 100 & $800 \pm 50$ & $90 \pm 10$ \\
\hline BXT5 & 3.7 & 88.9 & 3.1 & 2.8 & 1.4 & 0.1 & NA & 100 & $800 \pm 50$ & $90 \pm 10$ \\
\hline ВXТ6 & 3.7 & 88.9 & 3.1 & 2.8 & 1.4 & 0.1 & NA & 100 & $800 \pm 50$ & $90 \pm 10$ \\
\hline BXT7 & 3.7 & 88.8 & 3.2 & 2.8 & 1.4 & 0.1 & NA & 100 & $800 \pm 50$ & $90 \pm 10$ \\
\hline ВХТ8 & 3.7 & 88.4 & 3.7 & 2.8 & 1.4 & 0.1 & NA & 100 & $800 \pm 50$ & $90 \pm 10$ \\
\hline ВХТ9 & 3.6 & 86.8 & 3.6 & 4.5 & 1.4 & NA & 0.1 & 100 & $800 \pm 50$ & $90 \pm 10$ \\
\hline
\end{tabular}

a NA - polymer was not incorporated in agglomeration process.

BXH - bromhexine hydrochloride, HPMC 50 cps - hydroxypropyl methyl cellulose 50 cps, PEG 6000 - polyethylene glycol 6000, PVP K-30 - polyvinyl pyrrolidone K-30, PVA - polyvinyl alcohol.

rred for one min to form homogeneous paste (internal phase). At this step, mass gets dissolved in DCM, except talc. Walled baffle was then placed in the Morishima vessel, the aqueous solution of PEG $6000(15 \%, \mathrm{~m} / \mathrm{V}$, external phase, $100 \mathrm{~mL})$ prepared at $25^{\circ} \mathrm{C}$ was poured onto it and the whole mass was stirred continuously using a stirrer at $800 \pm$ 50 or $950 \pm 50 \mathrm{rpm}$ until spherical agglomerates were obtained.

By changing the percent of polymers, drug, talc and speed of agitation, nine batches of agglomerates, BXT1 to BXT9, were prepared. Upon completion of the agglomeration process, the whole mass was filtered and washed with the same filtrate. This was done to prevent loss of the drug and polymer from the agglomerate surface, which could happen by the use of fresh water. The details of the concentration of $\mathrm{BXH}$, talc, polymers and Tween 80 along with the conditions of agglomeration are given in Table I. In case of BXT1, the proportion of BXH to talc was kept 1:24, and for BXT2 it was 1:15.7. In batches, BXT3-BXT9, the percentage of HPMC 50 cps, polyvinyl pyrrolidone (PVP) K-30 and polyvinyl alcohol (PVA) varied, whereas the rest of the components and conditions of agglomeration were the same as that of batch BXT1.

\section{Surface topography}

The photomicrographs of BXT1 and BXT2 agglomerates were taken using an optical microscope (Motic Images Plus 2.0 ML, Motic China Group Co., China) at magnification of $4 \mathrm{X}$ and $10 \mathrm{X}$. 
N. Jadhav et al:: Effect of drug content and agglomerate size on tabletability and drug release characteristics of bromhexine hydrochloride-talc agglomerates prepared by crystallo-co-agglomeration, Acta Pharm. 60 (2010) 25-38.

\section{Fourier transform infrared spectroscopy (FTIR)}

FTIR spectra of BXH, talc, physical mixture (PM) of BXH, HPMC $50 \mathrm{cps}$, PEG 6000, talc and Tween 80 (having the same composition as that of BXT2) and spherical agglomerates (BXT2) were recorded using a FTIR spectrophotometer (Spectrum One FT-IR Spectrophotometer, Perkin Elmer Instruments, USA). FTIR spectra were recorded in $\mathrm{KBr}$ over the wavenumbers $450-4000 \mathrm{~cm}^{-1}$. Spectra obtained were comparatively analyzed.

\section{X-ray powder diffraction (XRPD)}

X-ray diffraction patterns of spherical agglomerates (BXT2), PM, BXH and talc were recorded using a Philips PW 1729 X-Ray diffractometer (Philips, The Netherlands). Samples were irradiated with monochromatized $\mathrm{Cu} \mathrm{K} \alpha$ radiation $(1.542 \AA)$ and analyzed between $10^{\circ}$ and $60^{\circ}(2 \theta)$. The voltage and current applied were $30 \mathrm{kV}$ and $30 \mathrm{~mA}$, respectively.

\section{Micromeritic properties}

Flowability assessment of BXT1 and BXT2 was done by the angle of repose (15), Carr's compressibility index (CCI) (16) and Hausner's ratio (HR) (17). Angle of repose $(\theta)$ was determined using the 'fixed funnel free standing cone method'. CCI and HR of agglomerates were determined from the values of bulk density and tapped density obtained with a bulk density apparatus (Lab Hosp, India) from 3 independent analyses. Initial volume of agglomerates before tapping $\left(V_{0}\right)$ and the volume after tapping $\left(V_{\propto}\right)$ were used to calculate the bulk and tapped density of agglomerates. Three size fractions of agglomerates having the mean geometric diameter (MGD) of 1327, 855, and $605 \mu \mathrm{m}$, respectively, of both agglomerate batches, were collected separately and subjected to micromeritic studies.

\section{Crushing strength studies}

Crushing strength $(C S)$ of BXT1 and BXT2 agglomerates was determined by the Jaroz and Parrots 'mercury load cell method' (18). Mesh fractions of agglomerates having MGD 1327, 855 and $605 \mu \mathrm{m}$ of both batches were collected separately. Randomly sampled 20 agglomerates from each mesh fraction were subjected to $C S$ determination and the average was taken to be CS. The logarithmic relationship was established between CS (in $\mathrm{N}$ ) and agglomerate size as shown by the following equation:

$$
\log C S=m \log D+C
$$

where $m$ is a slope and $C$ is intercept (constant) calculated by regression analysis of the $\log$ agglomerate diameter $D$ vs. $\log C S$. 
N. Jadhav et al:: Effect of drug content and agglomerate size on tabletability and drug release characteristics of bromhexine hydrochloride-talc agglomerates prepared by crystallo-co-agglomeration, Acta Pharm. 60 (2010) 25-38.

\section{Pressure-relative density relationship}

Intact agglomerates $(800 \pm 10 \mathrm{mg})$ of both batches BXT1 and BXT2 having MGD 1327, 855, and $605 \mu \mathrm{m}$ were separately compressed by a hydraulic press (Spectra Lab, India) using a 13-mm flat faced punch and die set at pressures of 8.79, 17.58, 26.37, 52.74 and 123.07 MPa for one min of dwell time. Lubrication of the die and punches was carried out using $1 \% \mathrm{~m} / \mathrm{V}$ homogenous dispersion of magnesium stearate in acetone. Compacts were allowed to relax for $24 \mathrm{~h}$ in vacuum at ambient temperature and the data obtained was subjected to the Heckel plot using the following equation (19):

$$
\ln \left(1 / 1-P_{\mathrm{f}}\right)=K P+A
$$

where $P_{\mathrm{f}}$ was packing fraction, $P$ applied pressure in MPa and $K=1 / 3 s_{0}$, where $s_{0}$ was yield strength and $3 \mathrm{~s}_{0}$ mean yield pressure $(P y), A$ was the intercept. The packing fraction was calculated by taking the ratio of compact density at different pressures to true density, 1, obtained at compression pressure of $123.07 \mathrm{MPa}$.

\section{Pressure-tensile strength relationship}

The same data used for the pressure relative density studies were used for the pressure-tensile strength (TS) relationship. Hardness of compacts was determined by a Monsanto type hardness tester (Kshitij Innovations, India) and used for TS determination according to equation (20):

$$
T S=2 F / \pi D t
$$

where $F$ is the crushing force in $\mathrm{N}, D$ and $t$ are the diameter and thickness of compacts, respectively, in $\mathrm{mm}$.

The effect of CS on TS of compacts was studied by equation:

$$
T S=d C S+C
$$

where $d$ was the slope and $C$ was a constant.

Simultaneously, the semi logarithmic relationship obtained between TS and $P_{\mathrm{f}}$ for each mesh fraction of both agglomerate batches was given by the following equation:

$$
\log T S=a P_{\mathrm{f}}+b
$$

where $a$ and $b$ were numerical constants depending on the binding between surfaces.

\section{Drug entrapment}

Drug entrapment study was carried in triplicate for agglomerats with MGD of 1327, 855 and $605 \mu \mathrm{m}$ for both batches. $200 \pm 10 \mathrm{mg}$ of agglomerates from each mesh fraction of 
N. Jadhav et al:: Effect of drug content and agglomerate size on tabletability and drug release characteristics of bromhexine hydrochloride-talc agglomerates prepared by crystallo-co-agglomeration, Acta Pharm. 60 (2010) 25-38.

both batches were weighed separately, powdered and added to $50 \mathrm{~mL}$ of $0.1 \mu \mathrm{mol} \mathrm{L}-1$ methanolic $\mathrm{HCl}$. The volume was adjusted to $100 \mathrm{~mL}$ by $0.1 \mu \mathrm{mol} \mathrm{L}-1$ methanolic $\mathrm{HCl}$ and filtered through Whatman filter paper No. 42. The filtrate was analyzed spectrophotometrically at $317 \mathrm{~nm}$ (Shimadzu 160, Japan). BXH content was determined from the standard curve using values of the slope, intercept and coefficient of correlation obtained as $119.658,0.051$ and 0.9999 , respectively.

\section{In vitro dissolution}

$\mathrm{BXH}$ release from agglomerates. $-300 \mathrm{mg}$ and $400 \mathrm{mg}$ of intact agglomerate mesh fractions $-10 /+16,-16 /+22$ and $-22 /+30$ (ASTM) of BXT1 and BXT2 respectively, were taken and subjected to dissolution studies in the United States Pharmacopoeia (21) dissolution test apparatus, type II (DA-6D, Veego Scientific, India) in triplicate. The study was carried out in $900 \mathrm{~mL}$ of $0.1 \mathrm{~mol} \mathrm{~L}^{-1} \mathrm{HCl}$ maintained at $37 \pm 0.5^{\circ} \mathrm{C}$ and stirred by paddles at 100 $\mathrm{rpm}$. The time required for complete dissolution of the drug from agglomerates was noted.

BXH release rate from compacts. $-300 \mathrm{mg}$ and $400 \mathrm{mg}$ of agglomerates having MGD 1327, 855 and $605 \mu \mathrm{m}$ from batch BXT1 and BXT2, respectively, were separately weighed and compressed using a hydraulic press at $35.16 \mathrm{MPa}$ pressure for $1 \mathrm{~min}$ of dwell time. The compacts obtained were allowed to relax for 24 hours in vacuum at ambient temperature and were subjected to dissolution studies similar to intact agglomerates in triplicate. Each time, $5 \mathrm{~mL}$ of sample was withdrawn and analyzed spectrophotometrically at $317 \mathrm{~nm}$ to obtain the amount of drug released. The same volume of fresh $0.1 \mathrm{~mol} \mathrm{~L}^{-1}$ $\mathrm{HCl}$ was used to replace the withdrawn sample. Data of the amount of drug released vs. time was subjected to software (PCP Disso, V.2.08, Poona College of Pharmacy, Pune, Maharashtra, India) for recording the drug release kinetics.

\section{RESULTS AND DISCUSSIONS}

\section{Process development studies}

At preliminary level, the CCA process was evaluated on the basis of the processability (stickiness), clarity of supernatant, percentage of fines generated, sphericity of agglomerates and agglomeration yield. Out of nine batches of agglomerates prepared, BXT1 to BXT9 (Table I), only BXT1 and BXT2 had spherical, non-sticky agglomerates, with supernatant free from fines upon completion of the agglomeration process. The other batches of agglomerates, BXT3 to BXT9, screened at preliminary level showed poor performance with respect to the aforementioned attributes. Either dispersion (emulsification) of the internal phase was incomplete or agglomerates were elliptical, sticky, and had more fines. Hence, further studies were performed for agglomerate batches BXT1 and BXT2 only. In the case of batch BXT1, the proportion of BXH-talc was kept low, 1:24, whereas for batch BXT2, it was 1:15.7 (higher amount of $\mathrm{BXH}$ ). The time required for completion of agglomeration was also longer for BXT2 (150 $\pm 10 \mathrm{~min})$ and stirring speed was $950 \pm 50 \mathrm{rpm}$. In batches BXT3 to BXT7, the low amount of HPMC (less than $3.6 \%$, $\mathrm{m} / \mathrm{m}$ ) incorporated led to formation of elliptical agglomerates with poor strength, which were difficult to filter and separate. It was noticed that these poor strength agglomerates 
N. Jadhav et al.: Effect of drug content and agglomerate size on tabletability and drug release characteristics of bromhexine hydrochloride-talc agglomerates prepared by crystallo-co-agglomeration, Acta Pharm. 60 (2010) 25-38.

led to deformation during the filtration stage, making separation of intact agglomerates difficult. In batch BXT8, comparatively higher percentage of HPMC $50 \mathrm{cps}(3.7 \%, \mathrm{~m} / \mathrm{m})$, despite having PVP K-30, did not allow complete emulsification of the internal phase, because of which large size agglomerates having a wider size distribution were generated and the yield was adversely affected. In batch BXT9, addition of PEG $6000(4.5 \%$, $\mathrm{m} / \mathrm{m})$ and PVA $(0.1 \%, \mathrm{~m} / \mathrm{m})$, both as dispersants, resulted in the formation of turbid supernatant. However, in batches BXT1 and BXT2, PEG 600 and Tween 80 carried out satisfactory emulsification of the internal phase in the absence of PVA. Consequently, the supernatant was not turbid. But, for batch BXT2, more BXH incorporated resulted in increased batch processing time.

\section{Surface topography}

Surface topography studies on the agglomerates of both batches showed perforations at the surface due to evaporation of DCM during the agglomeration process. Figs. $1 \mathrm{a}$ and $1 \mathrm{~b}$ clearly show the presence of small multiple holes at the surface of agglomerates of both batches, which are clearly seen in the magnified image (Fig. 1c).

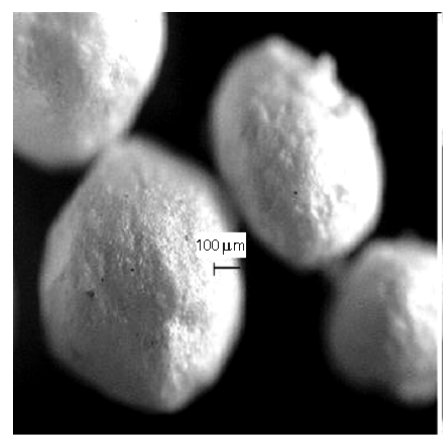

a)

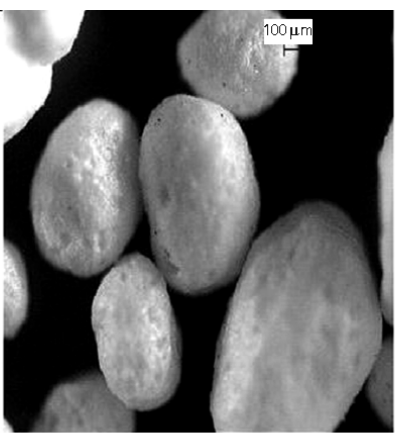

b)

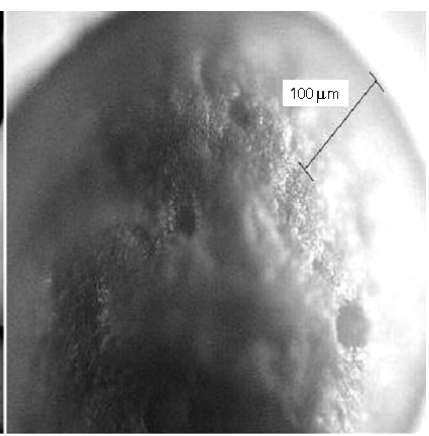

c)

Fig. 1. Photomicrographs of spherical agglomerates prepared by CCA: a) BXT1 at magnification 4X, b) BXT2 at magnification 4 X, c) BXT2 at magnification 10X.

\section{FTIR and XRPD}

FTIR spectra (Fig. 2a) of BXH show N-H stretching of primary amine at 3441.51 $\mathrm{cm}^{-1}$ and aromatic stretching of C-H at $3201.78,3232.20$ and $3301.55 \mathrm{~cm}^{1}$. Alkyl stretching of $\mathrm{CH}_{3}$ was seen at $2933.24 \mathrm{~cm}^{-1}$. N-H bending vibration of primary amine was seen at $1634.36 \mathrm{~cm}^{-1}$ and aromatic C-N stretching at $1350-1250 \mathrm{~cm}^{1}$. Stretching of C-Br was been observed at $690.29 \mathrm{~cm}^{-1}$ and cyclohexyl stretching at $1453.03 \mathrm{~cm}^{-1}$. In the case of agglomerates (Fig. 2d) and PM (Fig. 2c), an additional peak of strong $\mathrm{OH}$ bonding due to moisture was observed at 3677.29 and $3677.74 \mathrm{~cm}^{-1}$. NH stretching at 3444.86 and $3437.66 \mathrm{~cm}^{-1}$ indicated merging with $\mathrm{H}_{2} \mathrm{O}$. Alkyl C-H stretching vibration (moderate) was observed at the same wavenumbers both in PM and agglomerates. At $1000 \mathrm{~cm}^{-1}$, $\mathrm{Si}-\mathrm{O}$ vibration seen in talc (Fig. 2b) was noted in both PM and crystallo-co-agglomerates. 
N. Jadhav et al.: Effect of drug content and agglomerate size on tabletability and drug release characteristics of bromhexine hydrochloride-talc agglomerates prepared by crystallo-co-agglomeration, Acta Pharm. 60 (2010) 25-38.
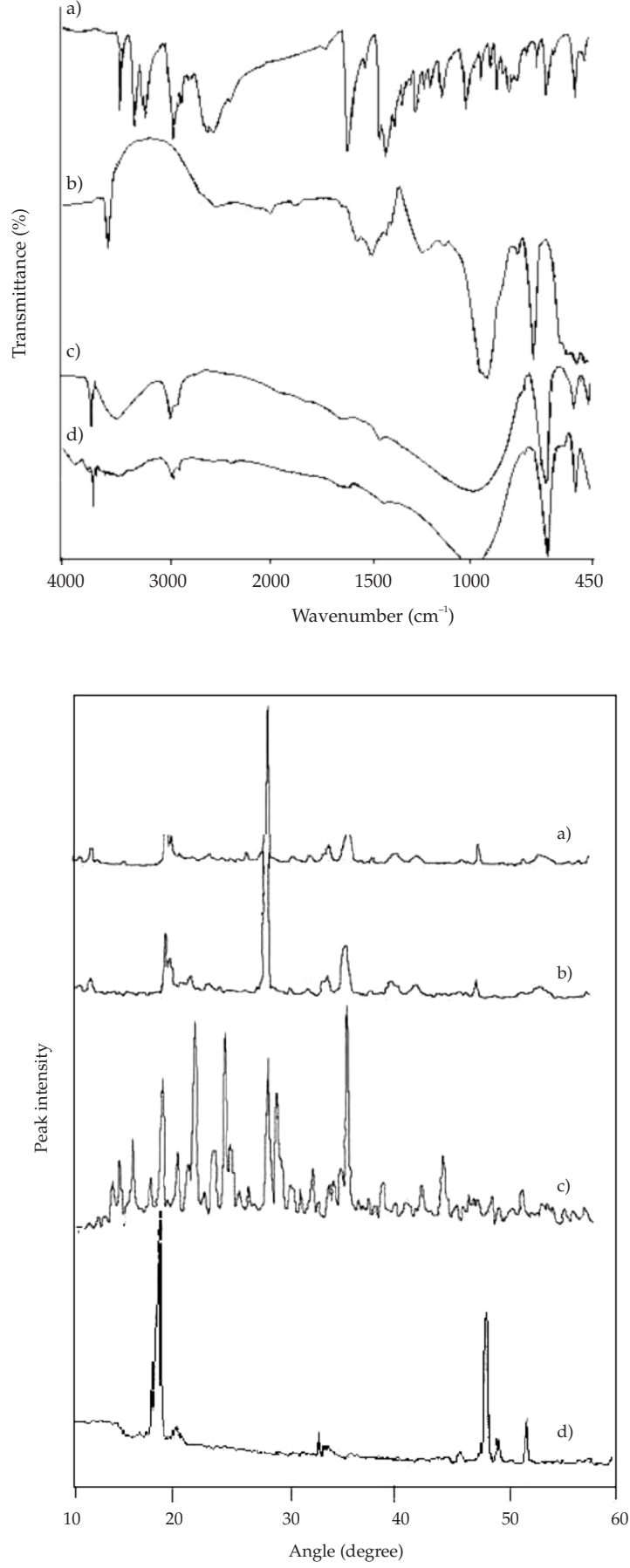

Fig. 2. FTIR spectra of: a) $B X H, b$ ) talc, c) PM, d) crystallo-co-agglomerated BXH.
Fig. 3. XRPD patterns of: a) crystallo-co-agglomerated $\mathrm{BXH}, \mathrm{b}$ ) $\mathrm{PM}, \mathrm{c}) \mathrm{BXH}, \mathrm{d})$ talc. 
N. Jadhav et al.: Effect of drug content and agglomerate size on tabletability and drug release characteristics of bromhexine hydrochloride-talc agglomerates prepared by crystallo-co-agglomeration, Acta Pharm. 60 (2010) 25-38.

Similar to $\mathrm{BXH}$ and talc, $\mathrm{NH}$ and $\mathrm{OH}$ bending vibrations, cycllohexyl and $\mathrm{C}-\mathrm{Br}$ stretching vibrations were also observed in PM and crystallo-co-agglomerates with a shift of wavenumbers. Dilution of BXH due to talc in PM and agglomerates has shown reduced transmittance at different wavenumbers.

The crystalline nature of BXH was confirmed from its XRPD pattern. Reduction in the peak intensity of $\mathrm{BXH}$ in PM and agglomerates was observed due to crystallinity reduction (Fig. 3). Even crystallinity of talc got reduced in PM and CCA form.

\section{Micromeritics and crushing strength}

Angle of repose $(\theta)$, Carr's compressibility index and Hausner's ratio have been used routinely to study the flowability and cohesivity of granules. Values of these micromeritic parameters are given in Table II. In case of BXT1 and BXT2, the value of $\theta$ was 25-35 and was changed with the change in the size of agglomerates. With a decrease in the size of agglomerates, $\theta$ gets increased. Although the difference in the value of $\theta$ between BXT1 and BXT2 was not statistically significant, it was statistically significant $(p<0.05)$ amongst 1327, 855 and $605 \mu \mathrm{m}$ size fractions of each agglomerate batch. The difference in the values of CCI for both agglomerate batches was not significant, but it was significant for agglomerates having the aforesaid mesh fractions. The HR value was $<1.18$, pointing to granules having excellent flowability. The effect of agglomerate size was significant on HR for both batches and the aforesaid size fractions ( $p<0.05$, Table II).

$C S$ of an agglomerate is an important parameter, reflecting the ease of agglomerate handling as well as its compressional behaviour. It has been observed that with a decrease in the size of agglomerates, the CS gets reduced irrespective of drug loading. With agglomerate size, the logarithmic relation was established by CS for both batches, BXT1 and BXT2.

The values of CS obtained for BXT1 and BXT2 agglomerates were $1.27 \pm 0.39$ and 1.31. $\pm 0.23 \mathrm{~N}$, respectively, indicating a pronounced effect of drug content on CS. Regression analysis of agglomerate size and CS [Eq. (1)] generated the values of slope $(m)$ $0.947 \pm 0.278$ for BXT1 and $0.331 \pm 0.097$ for BXT2. These slopes have demonstrated that, in batch BXT2, the change of CS with agglomerate size was less indicative of higher offered for crushing, compared to BXT1. Compared to batch BXT1, the decreased value of $m$, for batch BXT2, might have been due to the high amount of drug in the agglomerates. The difference between the values of CS for BXT1 and BXT2 was statistically significant at $p<0.05$. Moreover, the CS of agglomerates of different mesh fractions of each batch of agglomerates (intra-batch) was significantly different at $p<0.05$.

\section{Effect of pressure on relative density and tensile strength}

Heckel (19) has proposed a relation between the change in density (packing fraction) of solid and applied pressure. The values of $P y$ obtained from the Heckel equation [Eq. (2)] for different mesh fractions of both batches, BXT1 and BXT2, are reported in Table III. Values of Py obtained for BXT1 were less than for BXT2 due to lower drug content in agglomerates. In both batches, a trend of $P y$ value reduction with a decrease in agglomerate size was noted irrespective of the drug content of agglomerates. Better densification of small size agglomerates was clearly revealed by the data of $P y$ values given in Table III. The difference in Py values between BXT1 and BXT2 was statistically signifi- 
N. Jadhav et al:: Effect of drug content and agglomerate size on tabletability and drug release characteristics of bromhexine hydrochloride-talc agglomerates prepared by crystallo-co-agglomeration, Acta Pharm. 60 (2010) 25-38.

Table II. Drug entrapment and micromeritic properties of spherical agglomerates

\begin{tabular}{cccccccc}
\hline Batch & $\begin{array}{c}M G D \\
(\mu \mathrm{m})\end{array}$ & $\begin{array}{c}\text { Drug } \\
\text { entrapment }^{\mathrm{a}}(\%)\end{array}$ & $B D^{\mathrm{a}}$ & $T D^{\mathrm{a}}$ & $\theta^{\mathrm{a}}$ & $C C I^{\mathrm{a}}$ & $H R^{\mathrm{a}}$ \\
\hline \multirow{3}{*}{ BXT1 } & 1327 & $93.9 \pm 3.7$ & $0.95 \pm 0.00_{3}$ & $0.97 \pm 0.0_{1}$ & $26.82 \pm 0.34$ & $2.06 \pm 0.21$ & $1.03 \pm 0.00_{2}$ \\
& 855 & $95.5 \pm 1.6$ & $0.95 \pm 0.00_{2}$ & $1.02 \pm 0.0_{3}$ & $28.58 \pm 0.95$ & $6.86 \pm 0.08$ & $1.08 \pm 0.00_{1}$ \\
& 605 & $99.3 \pm 1.5$ & $0.95 \pm 0.01$ & $1.06 \pm 0.0_{2}$ & $33.49 \pm 0.19$ & $10.38 \pm 0.49$ & $1.12 \pm 0.01$ \\
& 1327 & $94.8 \pm 0.3$ & $0.93 \pm 0.01$ & $0.97 \pm 0.0_{4}$ & $27.10 \pm 0.52$ & $4.12 \pm 0.12$ & $1.04 \pm 0.00_{1}$ \\
BXT2 & 855 & $95.8 \pm 2.1$ & $0.94 \pm 0.00_{4}$ & $1.00 \pm 0.0_{1}$ & $28.96 \pm 0.96$ & $6.00 \pm 0.31$ & $1.07 \pm 0.00_{3}$ \\
& 605 & $99.3 \pm 1.1$ & $0.95 \pm 0.00_{2}$ & $1.09 \pm 0.0_{4}$ & $34.55 \pm 0.26$ & $12.84 \pm 0.14$ & $1.15 \pm 0.00_{2}$ \\
\hline
\end{tabular}

a Mean $\pm \mathrm{SD}, n=3$.

$M G D$ - mean geometric diameter, $B D$ - bulk density, $T D$ - tapped density, $\theta$ - angle of repose, $C C I$ - Carr's compressibility index, $H R$ - Hausner's ratio.

cant at $p<0.05$. The higher value of $P y$ for BXT2 could be attributed to low cohesiveness of $\mathrm{BXH}$.

TS of a compact is considered as the force per unit area of broken face required to split a powder compact [Eq. (3)]. Table III shows TS of compacts at constant $P_{\mathrm{f}}(0.9)$. It was observed that, with a decrease in the size of agglomerates, the TS got increased. In present case, it changed at a faster rate with agglomerate size in BXT2 because of increased drug loading leading to formation of crystal bridges due to drug-drug bonding.

Analysis of the data obtained from Eq. (4) has revealed that TS is a direct function of CS. However, the rate of change of TS with CS was high for batch BXT2. This might have been due to higher drug content of agglomerates causing better binding due to crystal bridges. Thus, TS gets increased with a decrease in particle size due to increased bonding surface area, confirming better packing. In the present case, a semi-logarithmic relationship was established between $P_{\mathrm{f}}$ and TS. Values of regression constants for Eq. (5) are given in Table IV. Rate of change of TS with $P_{\mathrm{f}}$ was found to get reduced with the decrease in the size of agglomerates irrespective of drug loading. The difference in values of slope (a) was statistically significant amongst size fractions 1327, 855 and $605 \mu \mathrm{m}$ for both batches at $p<0.05$.

Table III. Compression properties of BXH-talc agglomerates

\begin{tabular}{ccccc}
\hline \multirow{2}{*}{ MGD $(\mu \mathrm{m})$} & \multicolumn{2}{c}{ BXT1 } & \multicolumn{2}{c}{ BXT2 } \\
\cline { 2 - 5 } & $P y(\mathrm{MPa})^{\mathrm{a}}$ & TS at $0.9 P_{\mathrm{f}}(\mathrm{MPa})^{\mathrm{a}}$ & $P y(\mathrm{MPa})^{\mathrm{a}}$ & TS at $0.9 P_{\mathrm{f}}(\mathrm{MPa})^{\mathrm{a}}$ \\
\hline 1327 & $14.732 \pm 1.670$ & $0.340 \pm 0.008$ & $19.481 \pm 1.969$ & $0.633 \pm 0.019$ \\
855 & $12.606 \pm 1.530$ & $0.359 \pm 0.011$ & $16.896 \pm 1.670$ & $0.662 \pm 0.015$ \\
605 & $10.831 \pm 0.949$ & $0.374 \pm 0.015$ & $14.189 \pm 0.492$ & $0.751 \pm 0.150$ \\
\hline
\end{tabular}

a Mean $\pm \mathrm{SD}, n=3$.

$M G D$ - mean geometric diameter, $P y$ - mean yield pressure, TS at $0.9, P_{\mathrm{f}}$ - tensile strength at 0.9 packing fraction. 
N. Jadhav et al:: Effect of drug content and agglomerate size on tabletability and drug release characteristics of bromhexine hydrochloride-talc agglomerates prepared by crystallo-co-agglomeration, Acta Pharm. 60 (2010) 25-38.

Table IV. Regression analysis data for the packing fraction $\left(\mathrm{P}_{f}\right)$ and tensile strength (TS) of compacted agglomerates [data generated from Eq. (5)]

\begin{tabular}{ccccccc}
\hline \multirow{2}{*}{$\begin{array}{c}\text { MGD } \\
(\mu \mathrm{m})\end{array}$} & \multicolumn{4}{c}{ BXT1 } & \multicolumn{3}{c}{ BXT2 } \\
\cline { 2 - 7 } & $a^{\mathrm{a}}$ & $b^{\mathrm{a}}$ & $R^{\mathrm{a}}$ & $a^{\mathrm{a}}$ & $b^{\mathrm{a}}$ & $R^{\mathrm{a}}$ \\
\hline 1327 & $5.846 \pm 0.356$ & $-4.820 \pm 0.423$ & $0.911 \pm 0.030$ & $3.414 \pm 0.258$ & $-2.263 \pm 0.241$ & $0.881 \pm 0.048$ \\
855 & $3.773 \pm 0.145$ & $-6.132 \pm 0.325$ & $0.976 \pm 0.247$ & $3.104 \pm 0.125$ & $-1.961 \pm 0.199$ & $0.999 \pm 0.001$ \\
605 & $3.073 \pm 0.258$ & $-2.720 \pm 0.295$ & $0.961 \pm 0.032$ & $2.699 \pm 0.099$ & $-1.546 \pm 0.214$ & $0.974 \pm 0.011$ \\
\hline
\end{tabular}

MGD - mean geometric diameter, $a$ - slope, $b$ - constant intercept, $R$ - coefficient of correlation

a Mean $\pm \mathrm{SD}, n=3$.

\section{Drug entrapment and in vitro drug release studies}

The amount of drug entrapped in agglomerates of batches BXT1 and BXT2 was found to be dependent on the size of agglomerates. Table II clearly reveals the trend of increase in drug entrapment with a decrease in the size of agglomerates. The difference in the amount of drug entrapped amongst size fractions 1327, 855 and $605 \mu \mathrm{m}$ for both batches was found to be statistically significant $(p<0.05)$ and was highest $(99.3 \pm 1.50$ and $99.3 \pm$ $1.09 \%)$ for the smallest mesh fraction $(605 \mu \mathrm{m})$ of batches BXT1 and BXT2, respectively.

The $t_{90}$ (time required for $90 \%$ of drug to release) was used to study the drug release from agglomerates. Batch BXT1 showed $t_{90}$ as $10 \pm 2$ minutes, irrespective of the size of agglomerates, whereas, BXT2 showed $30.0 \pm 10.0,23.3 \pm 5.8,13.3 \pm 5.8$ minutes for size fractions 1327, 855 and $605 \mu \mathrm{m}$, respectively. Increase in the time required for complete drug release from agglomerates of BXT2 might have been due to more crystal bridges formed by crystallization of BXH during the agglomeration process. In both batches, BXT1 and BXT2, the presence of hydrophobic talc in agglomerates could not extend the release of BXH to a great extent due to formation of porous agglomerates (Figs. 1a, 1b, and 1c) and weak cohesive interactions. The images of porous agglomerates support rapid drug release from agglomerates containing the release controlling polymer (HPMC $50 \mathrm{cps})$ and hydrophobic talc.

Drug release from compacts can be extended with the help of different hydrophilic and hydrophobic polymers or combinations thereof in appropriate proportions. Incorporation of inert and inexpensive talc (diluent) as hydrophobic material with HPMC could be the best combination to reduce the percentage of polymer and achieve extended drug release. The present agglomeration technique holds a great challenge to generate extended release compacts from directly compressible spherical agglomerates at just $3.6 \%(\mathrm{~m} / \mathrm{m})$ of HPMC and high amounts of talc $(86.9 \%, m / m$, for BXT1 and $85.1 \%, m / m$, for BXT2). It was demonstrated that compacts of batch BXT1 extended the release of BXH up to 5 hours, whereas batch BXT2 extended drug release for up to 17 hours (Fig. 4).

Compacts prepared from smaller size agglomerates ( $605 \mu \mathrm{m}$ size) extended drug release most due to formation of extensive interparticulate bonding, as reflected in TS. In the present studies, the observed TS for BXT2 was greater than that for BXT1, resulting in extended drug release for a longer time. Higuchi matrix type of release was shown by compacts of both batches. Regression analysis of the Higuchi equation (Table V) showed that the difference between the values of $a$ amongst size fractions 1327,855 and $605 \mu \mathrm{m}$ 
N. Jadhav et al.: Effect of drug content and agglomerate size on tabletability and drug release characteristics of bromhexine hydrochloride-talc agglomerates prepared by crystallo-co-agglomeration, Acta Pharm. 60 (2010) 25-38.
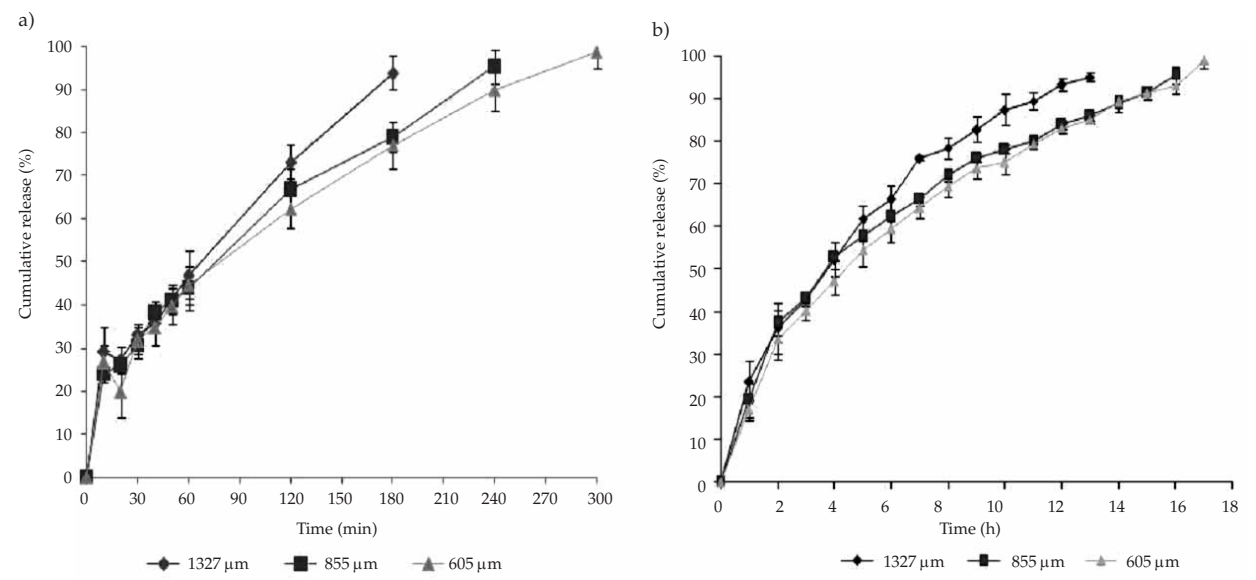

Fig. 4. Dissolution profile of compacted BXH-talc agglomerates prepared by CCA: a) BXT1, b) BXT2. Mean $\pm \mathrm{SD}, n=3$.

of each batch was statistically significant at $p<0.05$. Similarly, it was also statistically significant between BXT1 and BXT2. This indicates the predominant effect of drug content on the release rate due to formation of more solid bridges during the compaction process.

Table V. Regression analysis data for cumulative drug release (\%) and square root of time (Higuchi matrix model)

\begin{tabular}{|c|c|c|c|c|}
\hline \multirow{2}{*}{ Batch } & \multirow{2}{*}{ MGD $(\mu \mathrm{m})$} & \multicolumn{3}{|c|}{ Regression analysis constants for the Higuchi matrix model } \\
\hline & & $a^{\mathrm{a}}$ & $b^{\mathrm{a}}$ & $R^{2 \mathrm{a}}$ \\
\hline \multirow{3}{*}{ BXT1 } & 1327 & $5.388 \pm 0.386$ & $8.202 \pm 2.765$ & $0.984 \pm 0.013$ \\
\hline & 855 & $4.944 \pm 0.387$ & $6.053 \pm 4.665$ & $0.992 \pm 0.005$ \\
\hline & 605 & $4.756 \pm 1.213$ & $3.311 \pm 1.721$ & $0.994 \pm 0.005$ \\
\hline \multirow{3}{*}{ BXT2 } & 1327 & $3.693 \pm 1.034$ & $-10.873 \pm 8.418$ & $0.988 \pm 0.013$ \\
\hline & 855 & $2.826 \pm 0.191$ & $-6.089 \pm 3.654$ & $0.996 \pm 0.002$ \\
\hline & 605 & $2.555 \pm 0.281$ & $-4.140 \pm 4.284$ & $0.995 \pm 0.003$ \\
\hline
\end{tabular}

a Mean $\pm \mathrm{SD}, n=3$.

$a$ - slope, $b$ - constant intercept, $R^{2}$ - coefficient of determination.

\section{CONCLUSIONS}

Spherical agglomerates prepared by CCA have shown excellent flowability and strength, irrespective of the drug content of agglomerates. Despite the known poor cohesivity of $\mathrm{BXH}$, its role in improving tensile strength has been established. The effect of tensile strength in achieving extended drug release has also been noted. From the present studies, it can be concluded that poor strength and a large surface area of a spherical agglo- 
N. Jadhav et al.: Effect of drug content and agglomerate size on tabletability and drug release characteristics of bromhexine hydrochloride-talc agglomerates prepared by crystallo-co-agglomeration, Acta Pharm. 60 (2010) 25-38.

merate are responsible for its better compressibility, whereas the drug content determining tensile strength of a compact is responsible for extended drug release from the compact.

Acknowledgements. - The authors thank Colorcon Asia Pvt. Ltd., Mumbai, Maharashtra, for the sample of HPMC 50 cps.

\section{REFERENCES}

1. S. S. Kadam, K. R. Mahadik and A. R. Paradkar, A Process for Making Agglomerates for Use as Or in a Drug Delivery System, Indian Patent 183036, 14 Feb 1997.

2. S. S. Kadam, K. R. Mahadik and A. R. Paradkar, A Process for Making Agglomerates for Use as Or in a Drug Delivery System, Indian Patent 183481, 14 Feb 1997.

3. A. P. Pawar, Studies on Spherical Crystallisation of Various Pharmaceuticals [Ph. D. Thesis], Bharati Vidyapeeth, University of Pune, Pune 1999.

4. N. R. Jadhav, A. P. Pawar and A. R. Paradkar, Design and evaluation of deformable talc agglomerates prepared by crystallo-co-agglomeration technique for generating heterogeneous matrix, AAPS PharmSciTech. 8 (2007) Article 59; DOI: 10.1208/pt0803059.

5. A. P. Pawar, A. R. Paradkar, S. S. Kadam and K. R. Mahadik, Agglomeration of ibuprofen with talc by novel crystallo-co-agglomeration technique, AAPS PharmSciTech. 5 (2004) E55; DOI: 10. 1208/pt050455.

6. A. P. Pawar, A. R. Paradkar, S. S. Kadam and K. R. Mahadik, Crystallo-co-agglomeration: a novel process to obtain ibuprofen-paracetamol agglomerates, AAPS PharmSciTech. 5 (2004) E54; DOI: $10.1208 /$ pt050344.

7. A. P. Pawar, A. R. Paradkar, S. S. Kadam and K. R. Mahadik, Effect of polymers on crystallo-co-agglomeration of ibuprofen-paracetamol: factorial design, Indian. J. Pharm. Sci. 69 (2007) 658-664.

8. M. Maryam, T. Omid, G. Martin and A. Nokhodchi, Particle design of naproxen-disintegrant agglomerates for direct compression by a crystallo-co-agglomeration technique, Int. J. Pharm. 351 (2008) 123-133; DOI: 10.1016/j.jpharm.2007.09.033.

9. H. A. Garekani, J. L. Ford, M. H. Rubinstein and A. R. Rajabi-Siahboomi, Effect of compression force, compression speed and particle size on the compression properties of paracetamol, Drug Dev. Ind. Pharm. 27 (2001) 935-942; DOI: 10.1081/DDC-100107674.

10. E. Shotton and D. Ganderton, The strength of compressed tablets III. The relation of particle size, bonding and capping in tablets of sodium chloride, aspirin and hexamine, J. Pharm. Pharmacol. 13 (1961) 144-151.

11. H. Vormans, A. H. De Boer, G. Bolhuis, C. F. Lerk, K. D. Kussendrager and H. Bosch, Studies on tabletting properties of lactose. Part 2. Consolidation and compaction properties of different types of crystalline lactose, Pharm. Weekblad 7 (1985) 186-193.

12. K. Lin and G. E. Peck, Development of agglomerated talc. I. Evaluation of fluidized bed granulation parameters on the physical properties of agglomerated talc, Drug Dev. Ind. Pharm. 21 (1995) 159-173; DOI: 10.3109/03639049509026634.

13. K. Lin and G. E. Peck, Development of agglomerated talc. II. Optimization of the processing parameters for the preparation of granulated talc, Drug Dev. Ind. Pharm. 21 (1995) 447-460; DOI: $10.3109 / 03639049509048101$.

14. K. Morishima, Y. Kawashima, H. Takeuchi, T. Niwa and T. Hino, Micromeritic characteristics and agglomeration mechanisms in the spherical crystallization of bucillamine by the spherical agglomeration and the emulsion solvent diffusion methods, Powder Technol. 76 (1993) 57-64; DOI: 10.1016/0032-5910(93)80041-8. 
N. Jadhav et al:: Effect of drug content and agglomerate size on tabletability and drug release characteristics of bromhexine hydrochloride-talc agglomerates prepared by crystallo-co-agglomeration, Acta Pharm. 60 (2010) 25-38.

15. D. Train, Some aspects of the property of angle of repose of powders, J. Pharm. Pharmacol. 10 (1958) 127T-134T.

16. R. L. Carr, Evaluating flow properties of solids, Chem. Engineer. 72 (1965) 163-168.

17. H. H. Hausner, Friction conditions in a mass of metal powder, Int. J. Powder Metall. 3 (1967) 7-13.

18. P. J. Jaroz and E. J. Parrot, Comparison of granule strength and tablet strength, J. Pharm. Sci. 72 (1983) 530-535; DOI: 10.1002/jps.2600720513.

19. R. W. Heckel, Density pressure relationship in powder compaction, Trans. Metall. Soc. AIME 221 (1961) 671-675.

20. J. T. Fell and J. M. Newton, Effect of particle size and speed of compaction on density changes in tablets of crystalline and spray dried lactose, J. Pharm. Sci. 60 (1971) 1866-1869; DOI: 10.1002/ jps.2600601223.

21. United States Pharmacopoeia 32/National Formulary 27, USP Convention, Rockville 2009, p. 553.

$S A \check{Z} E T A K$

\section{Utjecaj sadržaja lijeka i veličine aglomerata na tabletiranje i oslobađanje bromheksin hidroklorida iz aglomerata s talkom pripremljenih kristalokoaglomeracijom}

NAMDEO JADHAV, ATMARAM PAWAR i ANANT PARADKAR

Cilj rada bio je praćenje utjecaja sadržaja bromheksidin hidroklorida (BXH) i veličine aglomerata na mehanička svojstva, kompresivnost i oslobađanje ljekovite tvari iz aglomerata pripravljenih kristalokoaglomeracijom (CCA). Optimizirani pripravci aglomerata (BXT1 i BXT2) pripravljeni CCA metodom pokazuju adekvatnu sferičnost i čvrstoću potrebnu za učinkovito tabletiranje. U oba pripravka se smanjenjem veličine aglomerata smanjivala i čvrstoća, neovisno o količini ljekovite tvari. Međutim, povećanje prosječnog tlaka s povećanjem veličine čestica primijećeno je u pripravku BXT2 s omjerom BXH-talk 1:15,7. Iznenađuje da su kompakti pripravljeni iz BXT2, s visokim sadržajem BXH, imali veću vlačnu čvrstoću, dok su BXT1 s niskim sadržajem BXH (BXH-talk, 1:24) imali manju čvrstoću. Veća vlačna čvrstoća imala je za posljedicu produljeno oslobađanje ljekovite tvari iz BXT2 (Higuchijev model, $R^{2}=0,9506$ do 0,9981). Može se zaključiti da mostovi među česticama BXH i veličina aglomerata utječu na njihova mehanička i kompresivna svojstva te na oslobađanje ljekovite tvari.

Ključne riječi: kristalokoaglomeracija, veličina aglomerata, sadržaj ljekovite tvari, kompresija, produljeno oslobađanje

Department of Pharmaceutics, Bharati Vidyapeeth College of Pharmacy, Kolhapur-416013, Maharashtra State, India

Department of Pharmaceutics, Poona College of Pharmacy, Bharati Vidyapeeth University, Erandwane Pune-411038, Maharashtra State, India

Institute of Pharmaceutical Innovation, University of Bradford, Bradford West Yorkshire, United Kingdom BD7 1DP 